\title{
Active Sites in Olefin Metathesis over Supported Molybdena
}

\section{Catalysts}

\author{
Kazuhiko Amakawa, ${ }^{[a]}$ Jutta Kröhnert, ${ }^{[a]}$ Sabine Wrabetz, ${ }^{[a]}$ Benjamin Frank, ${ }^{[a]}$ \\ Felix Hemmann, ${ }^{[b, c]}$ Christian Jäger,${ }^{[c]}$ Robert Schlögl, ${ }^{[a]}$ and Annette Trunschke ${ }^{*[a]}$
}

\begin{abstract}
Metathesis of propene to ethene and 2-butenes was studied over a series of $\mathrm{MoO}_{\mathbf{x}} / \mathrm{SBA}-15$ catalysts (molybdenum oxide supported on mesoporous silica SBA-15; Mo loading 2.1 13.3 wt \%, apparent Mo surface density $0.2 \sim 2.5 \mathrm{~nm}^{-2}$ ). The catalysts have been prepared by an ion exchange technique. Nitrogen adsorption, ${ }^{1} \mathrm{H}$ MAS-NMR, Raman, and FTIR spectroscopies were applied to characterize the catalysts. Adsorption of the reactant propene and the probe molecule $\mathrm{NH}_{3}$ was studied by in situ FTIR, microcalorimetry and temperature-programmed desorption. Irrespective of the loading, only ca. $1 \%$ of the Mo atoms in the $\mathrm{MoO}_{x} / \mathrm{SiO}_{2}$ catalysts transform into active carbene $(\mathrm{Mo}=\mathrm{CHR})$ sites catalyzing propene metathesis. Isolated, distorted molybdenum dioxo species in close vicinity to two silanol groups have been shown to be the precursor of the active site. Targeted active site creation by pretreatment with methanol resulted in an increase in initial catalytic activity by a factor of 800 .
\end{abstract}

\section{Introduction}

The current yearly production of C2-C4 olefins exceeds 200 million tons. Propene production by cross-metathesis of ethene and 2-butenes is an economic strategy to satisfy the increasing propene demand, ${ }^{[1]}$ where silica-supported tungsten oxide catalysts are currently employed at high temperature $(>573 \mathrm{~K}){ }^{[2]}$ It has been considered to substitute the $\mathrm{W}$-based catalysts by more active molybdenum oxides catalysts operating at mild conditions. $^{[3]}$ Supported molybdenum oxide catalysts exhibit the additional advantage that regeneration is possible. Recent studies suggest that Mo oxides supported on acidic materials (e.g., silica-alumina) are the most promising candidates. ${ }^{[4]}$ Metal-carbene species $(\mathrm{M}=\mathrm{CHR})$ are the active sites in olefin metathesis ${ }^{[5]}$ and they are generated in situ through surface

[a] Dr. K. Amakawa, J. Kröhnert, Dr. S. Wrabetz, Dr. B. Frank Prof. Dr. R. Schlögl, Dr. A. Trunschke

Department of Inorganic Chemistry

Fritz-Haber-Institut der Max-Planck-Gesellschaft

Faradayweg 4-6, 14195 Berlin (Germany)

E-mail: trunschke@fhi-berlin.mpg.de

[b] Dr. F. Hemmann, Prof. Dr. C. Jäger

BAM Federal Institute for Materials Research and Testing

Richard-Willstätter-Strasse 11, 12489 Berlin (Germany)

[c] Dr. F. Hemmann

Department of Chemistry

Humboldt-Universität zu Berlin

Brook-Taylor-Strasse 2, 12489 Berlin (Germany)

Supporting information for this article is given via a link at the end of the document reactions between the supported metal oxide and the olefin itself. Apparently, only a small fraction of metal atoms (ca. $1 \%$ in silicasupported molybdena catalysts) are involved in active site formation. ${ }^{[6]}$ Recently, we proposed a mechanism of the formation of $\mathrm{Mo}=\mathrm{CHR}$ sites in silica-supported molybdena, wherein $\mathrm{Mo}(\mathrm{VI})$ exclusively present in the freshly pretreated catalyst is reduced by propene to Mo(IV), which is followed by oxidative addition of another propene molecule to yield a surface $\mathrm{Mo}(\mathrm{VI})=\mathrm{CHR}$ species (as exemplified in Scheme 1a). ${ }^{[\mathrm{b}]}$ The mechanism postulates Brønsted acidity and oxidation ability of the catalyst. Though the general route of carbene generation was clarified, the structural identification of the relevant surface molybdenum oxide precursor species remains an elusive challenge, as it demands discrimination of a small minority (ca. $1 \%)$ from the majority of spectator species. As for aluminasupported molybdenum oxide catalysts the nature of the precursor structure has been controversially discussed, favoring both monomeric ${ }^{[7]}$ as well as oligomeric ${ }^{[8]}$ surface $\mathrm{MoO}_{x}$ species. Here, we study correlations between surface density of molybdenum oxide species, acid-base properties and catalytic properties taking a series of silica-supported molybdenum oxide catalysts with different Mo loading as basis. Combined application of spectroscopic and functional analyses allows us to further elucidate the nature of the active site precursor in olefin metathesis over supported molybdenum oxide catalysts.

\section{Results and Discussion}

Propene self-metathesis at $323 \mathrm{~K}$ over monolayer-type molybdena supported on meso-porous silica SBA-15 $\left(\mathrm{MoO}_{x} / \mathrm{SBA}-15\right)$ was studied as a model for the desired reverse reaction (i.e., propene production). The surface Mo density was varied changing the Mo content (Table 1) with the aim to identify the relevant pre-catalyst species that give active carbenes $(\mathrm{Mo}=\mathrm{CHR})$. A detailed structural characterization of the catalyst series by nitrogen adsorption, XRF, XRD, SEM-EDX, IR, Raman, UV-vis, O K-edge NEXAFS, Mo K-edge XANES/EXAFS and DFT calculations has been reported elsewhere. ${ }^{[9]}$

Textural properties of the $\mathrm{MoO}_{x} / \mathrm{SBA}-15$ catalysts are summarized in Table 1. The introduction of surface molybdenum oxide species at the expense of silanol groups results in a decrease of the specific surface area $A_{s}$ while preserving the large mesopores (ca. $7 \mathrm{~nm}$ ) of SBA-15. The decrease in the micropore surface area $A_{\mu}$ suggests a preferential anchorage of surface molybdena in the micropores.

The surface Mo density shows a great impact on the propene metathesis activity (Figures 1 (top)) The time trend of the fresh and regenerated catalysts that exhibits an increase in the 
propene metathesis with time on stream (constant activity after $15 \sim 21 \mathrm{~h}$ ) is presented in the supporting Information (Figure S1)

Table 1. Properties of $\mathrm{MoO}_{x} / \mathrm{SBA}-15$ catalysts

\begin{tabular}{llllllll}
$\begin{array}{l}\text { Mo } \\
\text { loading }{ }^{[\mathrm{a}]}\end{array}$ & Surface density & $A_{s}$ & $A_{\mu}^{[e]}$ & & $V_{p}^{[g]}$ & $d_{p}^{[\mathrm{n}]}$ \\
\hline$(\mathrm{wt} \%)$ & $\begin{array}{l}\mathrm{Mo}^{[\mathrm{b}]} \\
\left(\mathrm{nm}^{-2}\right)\end{array}$ & $\begin{array}{l}\text { Isolated } \\
\text { SiOH } \\
\left(\mathrm{nm}^{-2}\right)\end{array}$ & $\left(\mathrm{m}^{2} / \mathrm{g}\right)$ & $\left(\mathrm{m}^{2} / \mathrm{g}\right)$ & $(\%)^{[\mathrm{d}]}$ & $(\mathrm{ml} / \mathrm{g})$ & $(\mathrm{nm})$ \\
\hline 0 & 0 & $1.6^{[\mathrm{c}]}$ & 859 & 261 & 36 & 1 & 7.5 \\
2.1 & 0.21 & $1.1^{[\mathrm{d}]}$ & 637 & 164 & 31 & 0.79 & 7.1 \\
5.1 & 0.58 & $0.88^{[\mathrm{da}]}$ & 554 & 127 & 28 & 0.71 & 7.1 \\
6.6 & 0.85 & $0.68^{[\mathrm{d}]}$ & 490 & 135 & 28 & 0.61 & 7.1 \\
9.7 & 1.09 & $0.39^{[\mathrm{d}]}$ & 556 & 96 & 21 & 0.78 & 7.2 \\
13.3 & 2.51 & $0.07^{[\mathrm{da}]}$ & 332 & 36 & 13 & 0.55 & 7.4 \\
\hline
\end{tabular}

[a] by XRF. [b] Mo loading (at\%) divided by $A_{s}$. [c] by TG. [d] by IR at the dehydrated state using relative heights of the silanol peak at $3745 \mathrm{~cm}^{-1}$. [e] micropore ( $<\sim 0.9 \mathrm{~nm}$ of width) surface estimated by $t$-plot method. [f] $A_{\mu}$ divided by $A_{\mathrm{S}}$. [g] at $\mathrm{P} / \mathrm{P}_{0}=0.95$. [g] at the dehydrated state. [h] estimated by NLDFT approach.

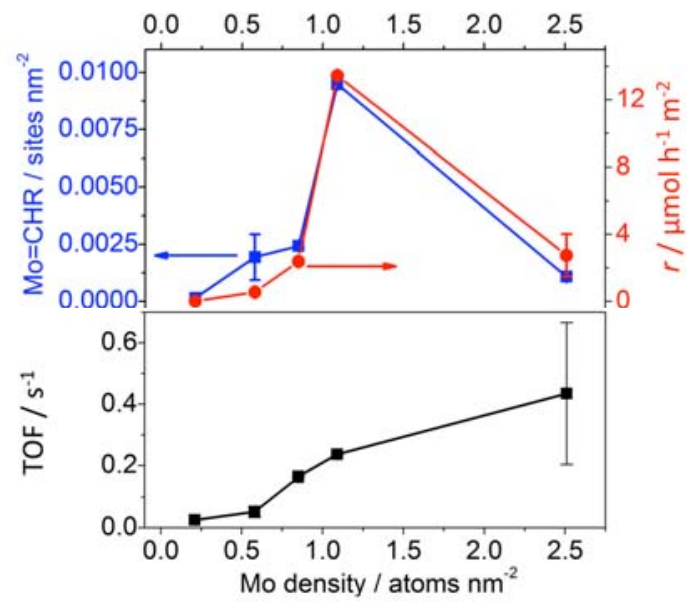

Figure 1. Propene metathesis performance of $\mathrm{MoO}_{x} / \mathrm{SBA}-15$ at $323 \mathrm{~K}$ measured after 15 21 $\mathrm{h}$ time on stream. (top) Metathesis rate and surface concentration of active carbene sites $(\mathrm{Mo}=\mathrm{CHR})$. (bottom) Turnover frequency (TOF). Error bars are estimated by two repeated measurements using fresh and regenerated catalysts. The catalysts were pretreated or regenerated in $20 \% \mathrm{O}_{2}$ at $823 \mathrm{~K}$ for $0.5 \mathrm{~h}$.

The surface concentration of active carbene species (Figure 1 (top), blue line) determined by post-reaction titration by ethene$\mathrm{d}_{4}$ metathesis $^{[6 \mathrm{bb}]}$ is at most $1 \%$ of all surface Mo atoms and coarsely follows the trend of the activity (Figure 1 (top), red line), indicating that the number of active sites is the dominant factor for activity. Dividing the rate by the active site density yields the turnover frequency (TOF; Figure 1 (bottom)), which shows a significant increase with increasing Mo density. The Mo density evidently affects both the probability of active site formation and the intrinsic metathesis activity (i.e., TOF) of the $\mathrm{Mo}=\mathrm{CHR}$ species (Figure 1). Propene adsorption studies were performed to explain this pattern. The carbene generation process was traced upon propene adsorption by in situ FTIR spectroscopy and microcalorimetry (Figure 2).

Bands due to C-H vibrations (stretching : 2983, 2939, $2880 \mathrm{~cm}^{-1}$; deformation: $\left.1465,1455,1389,1375 \mathrm{~cm}^{-1}\right)$ and $\mathrm{v}(\mathrm{C}=\mathrm{O})$ at 1668 $\mathrm{cm}^{-1}$ in the infrared spectra (Figure 2a) are assigned to isopropoxide and acetone, respectively. ${ }^{[6]}$ Formation of these intermediates indicates the protonation of propene to isopropoxide and its subsequent oxidation to acetone, where Brønsted acidity and oxidation ability of surface molybdena are involved (Scheme 1a; 1 to 4). This finding agrees with our previous study that included only a single catalyst with Mo density of $1.1 \mathrm{Mo} \mathrm{nm}^{-2}{ }^{[6 \mathrm{~b}]}$ The intensity of the observed bands does not follow the Mo surface density. a)

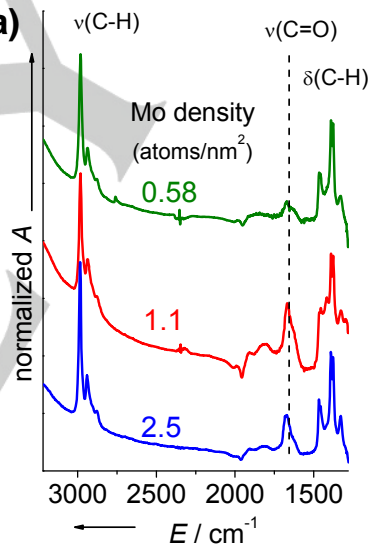

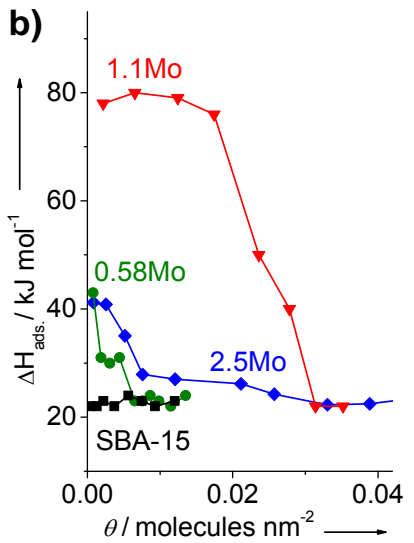

Figure 2. Adsorption of propene on $\mathrm{MoO}_{x} / \mathrm{SBA}-15$ with different Mo loadings at $323 \mathrm{~K}$. (a): FTIR spectra collected after propene dosing at $3 \mathrm{hPa}$ for $18 \mathrm{~h}$ and subsequent evacuation. (b): Differential heat of propene adsorption as a function of coverage determined by microcalorimetry. Surface Mo density (Mo atoms $\mathrm{nm}^{-2}$ ) is indicated close to the data.

The quantity and strength of the propene adsorption sites were evaluated by microcalorimetry (Figure $2 b$ ). Heat of adsorption as well as amount of adsorbed propene do also not follow the trend in surface Mo density but increase in the order $0.58 \mathrm{Mo} \cong$ $2.5 \mathrm{Mo}<1.1 \mathrm{Mo}$. A similar tendency is observed in the overall rate and the number of surface carbene species (Figure 1(top)). Such a positive correlation between the surface concentration of $\mathrm{Mo}=\mathrm{CHR}$ species in catalysis and the number as well as the strength (i.e., heat of adsorption) of propene adsorption sites is also shown in the supporting (Figure S2). The observation suggests the involvement of the corresponding propene 
adsorption sites in the generation of active species. The surface concentration of $\mathrm{Mo}=\mathrm{CHR}$ is significantly lower than the overall number of propene adsorption sites (Figure S2b), confirming that only a fraction of the adsorbed propene yields the active sites

Bi-functionality of the catalyst in terms of acidity (protonation of propene to isopropoxide) and redox activity (oxidation of isopropoxide to acetone) is considered to be indispensable for the carbene generation. ${ }^{[6 b]}$ To identify the nature of the Brønsted acid sites, hydrogen species were characterized by ${ }^{1} \mathrm{H}-\mathrm{NMR}$ (Figure 3). While bare SBA-15 possesses virtually isolated silanol groups only (Figure 3a, $1.75 \mathrm{ppm}$ ), ${ }^{[10]}$ the loading of surface molybdenum oxide species leads to an occurrence of hydrogen-bonded silanol groups (Figure $3 a$, broad band at 2-5 $\mathrm{ppm}),{ }^{[10]}$ and a perturbation of isolated silanol (i.e., shift to 1.93 $\mathrm{ppm}$ ). The results are consistent with the structural analysis by Raman, IR, UV-Vis, Mo K-edge XANES/EXFAS, O K-edge NEXAFS, and DFT calculations, ${ }^{[9]}$ which show the formation of two-fold anchored tetrahedral di-oxo $(\mathrm{Si}-\mathrm{O}-)_{2} \mathrm{Mo}(=\mathrm{O})_{2}$ structures as the predominant surface molybdenum oxide species at the expense of surface silanol groups at all loadings. A fraction of the residual silanol groups is in hydrogen bonding with these molybdenum oxide species. The fraction of $\mathrm{OH}$ groups adjacent to molybdenum oxide species becomes smaller with increasing Mo surface density.
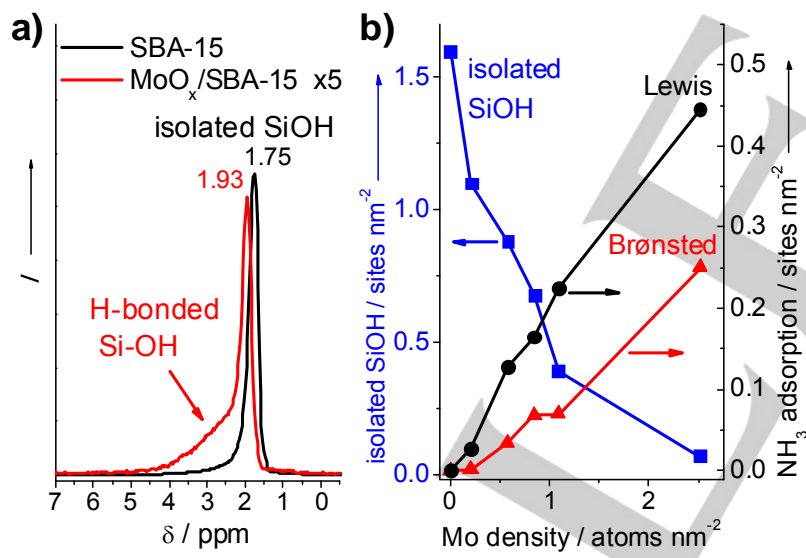

c)

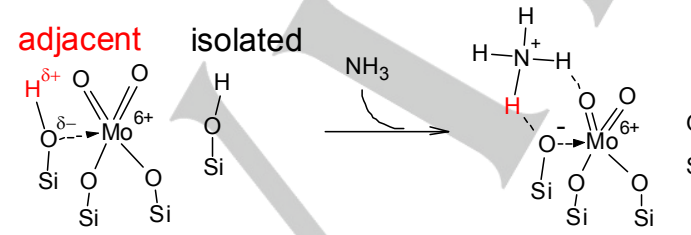

Figure 3. Study on acidity and hydroxyl groups in $\mathrm{MoO}_{x} / \mathrm{SBA}-15$. (a): ${ }^{1} \mathrm{H}-\mathrm{MAS}$ NMR spectra of SBA-15 and MoO $/$ SBA-15 (1.27 Mo atoms $\mathrm{nm}^{-2}$ ). The spectrum of $\mathrm{MoO}_{x} / \mathrm{SBA}-15$ is magnified by factor of 5 . (b): Density of isolated silanol groups and ammonia adsorption sites estimated by IR. (c): Schematic illustration of the suggested model for Brønsted acid sites. The original IR spectra are presented in the Supporting Information (Figure S3). The catalysts were pretreated in pure $\mathrm{O}_{2}$ at 823 for $0.5 \mathrm{~h}$.
Probing the acid sites by ammonia adsorption monitored by IR reveals a monotonous increase of the surface concentration of both Brønsted and Lewis acid sites (coordinatively unsaturated Mo centers) with increasing Mo density, where at most $10 \%$ of total Mo atoms serve as Brønsted acid sites (Figures 3b, and S3). Note that extinction coefficients used for calculating the surface concentration of Brønsted and Lewis acid sites have been taken from literature. ${ }^{[11]}$ Consequently, the analysis represents just a rough estimation.

Provided no indication for the presence of molybdenol groups by ${ }^{1} \mathrm{H}-\mathrm{NMR}$ (Figure 3a; $\mathrm{Mo}-\mathrm{OH}$ likely occurs below $1 \mathrm{ppm}^{[12]}$ ) and by other spectroscopic characterization, ${ }^{[9]}$ silanol sites in the vicinity of surface molybdena species are the most likely and actually the only possible source of Brønsted acidity. Analogously to Brønsted acid sites in silica-alumina materials, ${ }^{[13]}$ the conjugated Brønsted base ammonia appears to be protonated in a bonding configuration that is illustrated in Figure 3c. The hydrogen atom of the silanol group in close vicinity to a surface molybdena species interacts with the nitrogen atom of ammonia, because it bears a partial positive charge due to the interaction of the oxygen atom in the $\mathrm{OH}$ species with the adjacent Lewis acidic Mo site. At the same time, the ammonia molecule undergoes hydrogen-bonding to a terminal oxygen atom of the surface molybdenum oxide species. Such a configuration may have an unknown impact on the extinction coefficient of the ammonium species, and, consequently, on the quantification of Brønsted acid sites by ammonia adsorption. The uncertainty is reflected by the observation that the overall acid strength (i.e., including the Lewis sites) estimated by temperature-programmed desorption of ammonia (Figure S4) appears to be similar for all catalysts, i.e., the trends in ammonia adsorption seem to be dominated by weak adsorption of $\mathrm{NH}_{3}$ on Lewis acid sites.

In summary, ${ }^{1} \mathrm{H}-\mathrm{NMR}$ and FTIR indicate that Brønsted acidity in silica-supported $\mathrm{MoO}_{\mathrm{x}}$ arises from silanol groups that are located in close proximity to surface molybdenum oxide species. Propene adsorption allows the semi-quantitative estimation of relevant acidity when taking into account that propene adsorption sites exhibit a heat of adsorption higher than $30 \mathrm{~kJ}$ $\mathrm{mol}^{-1}$. The propene uptake represents at most $3 \%$ of total Mo atoms and shows a non-linear dependence to the Mo density (Figures $\mathrm{S} 2$, and $2 \mathrm{~b} ; \sim 0.03 \mathrm{C}_{3} \mathrm{H}_{6}$ molecules $\mathrm{nm}^{-2}$ for $1.1 \mathrm{Mo}$ atoms $\mathrm{nm}^{-2}$ ), in which the maximum has been found at a Mo density of 1.1 atoms per $\mathrm{nm}^{2}$, which corresponds to the most active catalyst.

To transform propene to acetone (Scheme 1a; 3 to 4), the isopropoxide species formed at a Brønsted acidic silanol site needs to migrate to a $\mathrm{Mo}(\mathrm{VI})$ center that exhibits oxidation ability. Such migration of surface alkoxide species across silanol sites and molybdenum oxide sites was observed by in situ IR using isotope labeling. ${ }^{[14]}$ However, the underlying mechanism remains unclear. The IR data show an increased acetone formation at high Mo density (Figure 2a; $\mathrm{v}(\mathrm{C}=\mathrm{O})$ at $1668 \mathrm{~cm}^{-1}$ ), suggesting a higher probability of the migration, which is in line with the increased reactivity of the surface molybdenum oxide species due to the increased strain at the anchoring Mo-O-Si bonds that has been observed by $\mathrm{O} \mathrm{K}$-edge NEXAFS in combination 
with DFT calculations. ${ }^{[9]}$ Based on the IR observation and the structural characterization, we propose that the migration involves a breaking of a Mo-O- $-\mathrm{Si}$ bond and concurrent formation of a Si-O-Si bond (Scheme 1a, 2 to 3), wherein a high strain at Mo-O- $\mathrm{Si}$ emerging at high Mo density is expected to be a key driving force of the rearrangement event.

a) In Situ Carbene Generation in Propene Metathesis

1

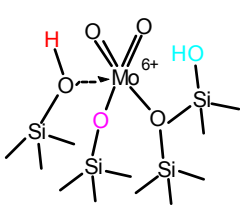

5

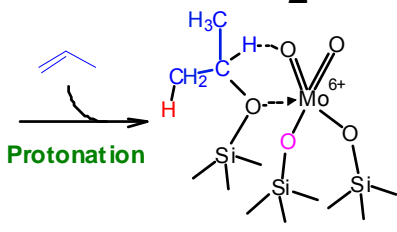

6
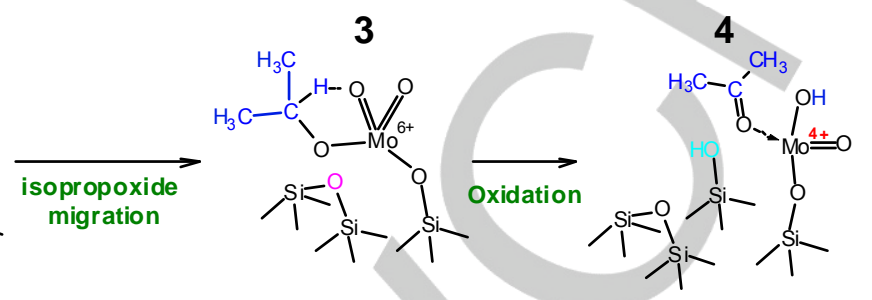

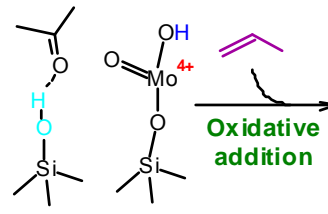

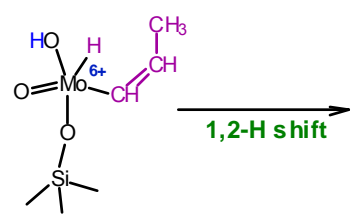

7

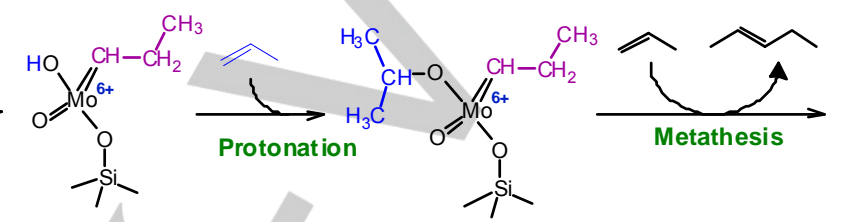

9

b) Carbene Creation Assisted by Methanol Pretreatment

1

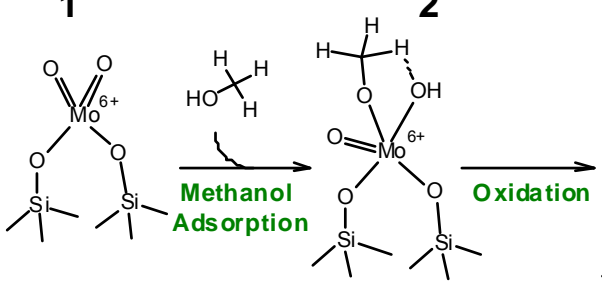

3

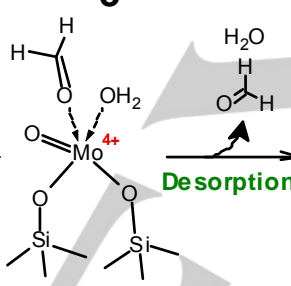

4
5 acetone migration

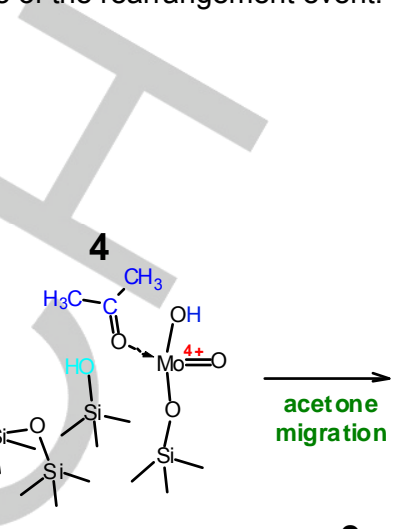

pretreatment.

The formed acetone needs to desorb to allow access of another propene molecule to the $\mathrm{Mo}(\mathrm{IV})$ center that leads to the formation of active $\mathrm{Mo}(\mathrm{VI})=\mathrm{CHR}$ sites (Scheme $1 \mathrm{a}, 4$ to 5 ). These processes are expected to occur simultaneously, as it was show recently for the exchange of pyridine at acid sites. ${ }^{[15]}$ The desorption of acetone upon heating after catalysis (Figure S5) suggests a reversible capture of acetone by hydrogenbonding at silanol groups ${ }^{[16]}$ in the vicinity to the molybdena sites. ${ }^{[6 \mathrm{~b}]}$ The low activity at the highest Mo density (Figure 1a) may be, therefore, related to the low silanol density due to the extensive coverage of the support by molybdenum oxide species (Figure 3b).

Summarizing the structural assignments for the required functions for carbene generation on silica-supported molybdenum oxide catalysts, a model for the catalyst precursor is envisaged. This model (Scheme $1 \mathrm{a}, \mathbf{1}$ ) is characterized by a $(\mathrm{Si}-\mathrm{O}-)_{2} \mathrm{Mo}(=\mathrm{O})_{2}$ structure exhibiting high strain at the Mo$\mathrm{O}-\mathrm{Si}$ bonds $^{[9]}$ surrounded by at least two adjacent silanol groups that equip Brønsted acidity and a trapping function for the by-product acetone. Following the sequential reactions discussed above, a mono-anchored tetrahedral Mo(VI)- propylidene is expected to occur (Scheme 1a, 7), which may further undergo the alkoxide formation (Scheme 1a, 8) and transformation to $\mathrm{Mo}(\mathrm{VI})$-methylidene by propene metathesis (Scheme 1a, 9). The strained molybdena species occur at relatively high Mo density, ${ }^{[9]}$ while it still needs adjacent silanol sites to form the active sites. This accounts for the presence of an optimum Mo density at sub-monolayer coverage (Figure 1a). The low intrinsic activity at low Mo density (Figure 1b) may be due to increased steric hindrances by abundant silanol groups surrounding the carbene center and blocking the access of propene $^{[17]}$ and/or subtile variations in the geometric configuration (e.g., bond lengths and angles), ${ }^{[16,17]}$ as suggested by theoretical studies. ${ }^{[18]}$

The population balance of surface molybdenum oxide species and surrounding silanol groups is reflected in the $\mathrm{v}(\mathrm{Mo}=\mathrm{O})$ stretching frequency in vibrational analysis. The original spectra $^{[9]}$ are presented in the Supporting Information (Figure S6). With increasing molybdenum loading, the $\mathrm{v}_{\mathrm{s}}(\mathrm{Mo}=\mathrm{O})$ Raman band at 980-997 $\mathrm{cm}^{-1}$ becomes sharper and is blue-shifted (Figure S6a), which is also observed in the corresponding infrared spectra (Figure S6b). The v(Mo-O-Si) band at 926- 
$943 \mathrm{~cm}^{-1}$, visible in the infrared spectra (Figure S6b), is also blue-shifted. The blue shift of the bands with increasing Mo loading indicates the decrease of hydrogen bonding due to surrounding silanol groups since fewer silanol groups are available with increasing molybdenum oxide loading. A clear structure-activity relationship exhibiting a volcano-type profile (Figure 4) suggests the presence of an optimum degree of hydrogen bonding of surface molybdena species, supporting the hypothesis that molybdena-silanol ensembles are precursors of the active sites.

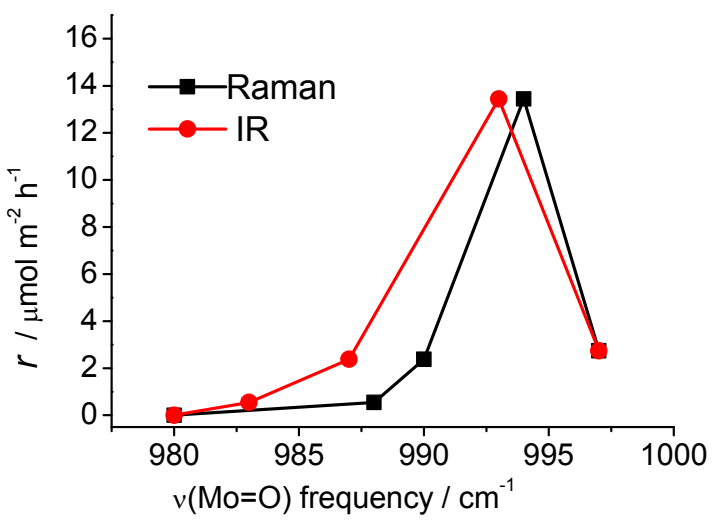

Figure 4. Correlation between the $\mathrm{v}(\mathrm{Mo}=\mathrm{O})$ frequency detected in Raman/IR analysis and propene metathesis activity of $\mathrm{MoO}_{\times} / \mathrm{SBA}-15$ at $323 \mathrm{~K}$ and at $15 \sim 21 \mathrm{~h}$ time on stream. The catalysts were pretreated or regenerated in $20 \%$ $\mathrm{O}_{2}$ at $823 \mathrm{~K}$ for $0.5 \mathrm{~h}$. The vibrational spectra are presented in the Supporting Information (Figure S6)

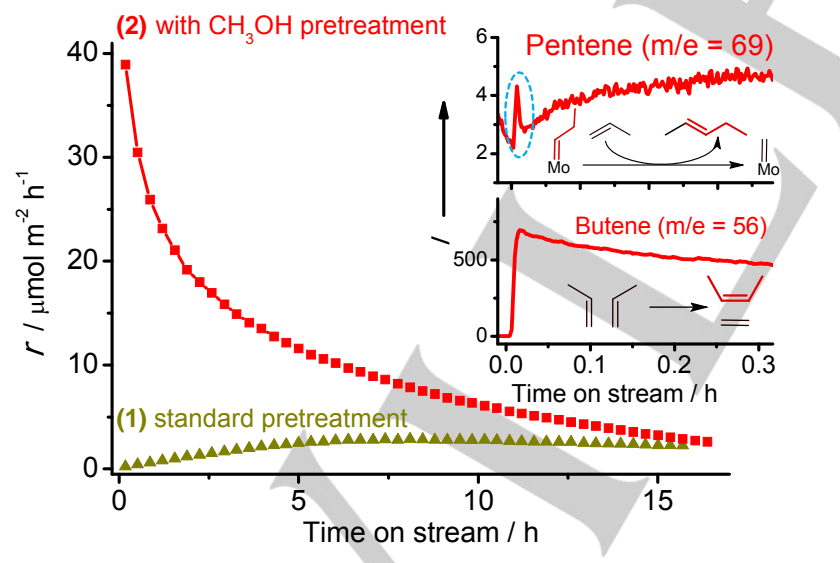

Figure 5. Propene metathesis activity of a $\mathrm{MoO}_{x} / \mathrm{SBA}-15$ catalyst $(0.85 \mathrm{Mo}$ atoms $\mathrm{nm}^{-2}$ ) after different pretreatment procedures. (1) Standard pretreatment $\left(20 \% \mathrm{O}_{2}, 823 \mathrm{~K}, 0.5 \mathrm{~h}\right)$. (2) Methanol pretreatment $\left(4 \% \mathrm{CH}_{3} \mathrm{OH} / \mathrm{Ar}, 523 \mathrm{~K}, 0.5\right.$ h) and subsequent desorption (Ar, $823 \mathrm{~K}, 0.5 \mathrm{~h}$ ) after the standard pretreatment. The inset shows signal of mass spectrometer for $\mathrm{m} / \mathrm{e}=69$ (pentene) and $\mathrm{m} / \mathrm{e}=56$ (butenes) at the initial period of the reaction after methanol pretreatment.
Having understood the mechanism of carbene generation, controlled active site creation is feasible. To enhance the formation of coordinatively unsaturated $\mathrm{Mo}(\mathrm{IV})$ sites, the catalyst was first treated with methanol at $523 \mathrm{~K}$ followed by a heat treatment in $\mathrm{Ar}$ at $823 \mathrm{~K}$. The reduction of the abundant di-oxo $(\mathrm{Si}-\mathrm{O}-)_{2} \mathrm{Mo}(=\mathrm{O})_{2}$ species by methanol does not require Brønsted acidity, ${ }^{[19]}$ leaving coordinatively unsaturated $\mathrm{Mo}(\mathrm{IV})$ sites after the desorption of by-products in the post-treatment in $\operatorname{Ar}$ (Scheme 1b, 1 to 4). This procedure increases the initial catalytic activity by a factor of 800 (Figure 5). The high initial activity allows detection of the temporal formation of pentene at the initial period of the reaction (Figure 5, inset), which indicates the occurrence of $\mathrm{Mo}(\mathrm{VI})$-propylidene species (Scheme 1b, 5) that corroborates the suggested mechanism of carbene formation. A continuous deactivation was observed in the case of the methanol pretreatment, implying that the anticipated twofold anchored $\mathrm{Mo}(\mathrm{VI})$-carbene (Scheme $1 \mathrm{~b}, 6$ ) is less stable than the mono-hapto structure (Scheme 1a, 9). Indeed, the gradual deactivation of the two-fold anchored tetrahedral $\mathrm{Mo}(\mathrm{VI})$ - carbene was reported previously, ${ }^{[20]}$ whereas monoanchored Schrock-type Mo(VI)—alkylidene on dehydroxylated silica, which is similar to the anticipated structure in the case of the standard pretreatment (Scheme 1a, 9), exhibits a stable activity. ${ }^{[21]}$

\section{Conclusions}

In summary, we specified the structures of the active sites for propene metathesis in $\mathrm{MoO}_{x} / \mathrm{SBA}-15$ by integrating the inputs from quantification of active sites, probe molecule adsorption and structural characterization. We propose that ensembles of strained, two-fold anchored tetrahedral di-oxo (Si-O)$_{2} \mathrm{Mo}(=\mathrm{O})_{2}$ structures and adjacent silanol groups represent the precursor of the active carbene species. The suggested prominent role of adjacent silanol groups may help to understand the beneficial effect of using acidic supports. ${ }^{[4]}$ The obtained insights pave the way for evolution of metathesis catalysts by rational approaches, as has been exemplified in Figure 5.

\section{Experimental Section}

\section{Preparation of the $\mathrm{MoO}_{\mathrm{x}} / \mathrm{SBA}-15$ catalysts}

The $\mathrm{MoO}_{\mathrm{x}} / \mathrm{SBA}-15$ catalysts (molybdena supported on mesoporous silica SBA-15; Mo loading 2.1 13.3 wt\%) were prepared by an ion exchange protocol. ${ }^{[22]}$ The details of the preparation were described elsewhere. ${ }^{[9]}$ In brief, freshly synthesized metal-free SBA-15 (internal sample ID 8233) was functionalized with propylammonium chloride using (3aminopropyl)trimethoxysilane followed by treatment with hydrochloric acid. Then, the functionalized SBA-15 powder was stirred in an aqueous solution containing the desired amount of ammonium heptamolybdate to perform an anion exchange. After washing with water and filtration, the material was dried and calcined at $823 \mathrm{~K}$ in air, yielding supported $\mathrm{MoO}_{\mathrm{x}} / \mathrm{SBA}-15$ with the actual Mo loadings of 2.1, 5.1, 6.6, 9.7 and $13.3 \%$ (internal sample ID $8442,8440,11054,8438,8441$, respectively). 
The properties of the catalysts are summarized in Table 1. Additionally, a SBA-15 (BET surface are $=833 \mathrm{~m}^{2} / \mathrm{g}$, internal ID 8261) and a $\mathrm{MoO}_{x} / \mathrm{SBA}-15\left(\mathrm{BET}\right.$ surface are $=532 \mathrm{~m}^{2} / \mathrm{g}, 10.8 \mathrm{Mo} \%, 1.27 \mathrm{Mo} / \mathrm{nm}^{2}$ internal ID 13578) were prepared using the same procedure but in different batches for the ${ }^{1} \mathrm{H}-\mathrm{NMR}$ study.

\section{Characterization of the $\mathrm{MoO}_{\mathrm{x}} / \mathrm{SBA}-15$ catalysts}

\section{Nitrogen adsorption Nitrogen adsorption was carried out at 77} K on a Quantachrome Autosorb-6B analyzer. Prior to the measurement, the samples were outgassed in vacuum at $393 \mathrm{~K}$ for $16 \mathrm{~h}$. The data were processed on Autosorb software (Quantachrome). The specific surface area $A_{s}$ was calculated according to the multipoint Brunauer-EmmettTeller method (BET) in the pressure range $\mathrm{p} / \mathrm{p} 0=0.05-0.15$ assuming a $\mathrm{N}_{2}$ cross sectional area of $16.2 \AA^{2}$. The micropore surface area $A_{\mu}$ and micropore volume $V_{\mu}$ were estimated using the $t$-plot method in the statistical thickness $t=4.5-6.5 \AA$ range. The total pore volume $V_{p}$ was estimated by using the amount of physisorbed nitrogen at a relative pressure $p / p_{0}=0.95$. The pore size distribution was determined by NLDFT method using a model based on equilibrated adsorption of $\mathrm{N}_{2}$ on silica assuming cylindrical pores at $77 \mathrm{~K}$.

${ }^{1} \mathrm{H}$-NMR Solid-state magic angle spinning (MAS) NMR experiments were performed on a Bruker DMX 400 spectrometer (400.1 $\mathrm{MHz}, 9.4 \mathrm{~T}$ ) at room temperature. Measurements were run with single pulse excitation using a MAS frequency of $12.5 \mathrm{kHz}$. The ${ }^{1} \mathrm{H}$ background signal of the probe was corrected by subtracting the ${ }^{1} \mathrm{H}$ MAS NMR spectrum of an empty rotor. ${ }^{1} \mathrm{H}$ chemical shifts were referenced versus adamantane. The pretreated samples were transferred into an air-tight rotor in a glove box to avoid exposure to air. Approximately the same amount of sample was charged into the rotor for every experiment.

FTIR Diffuse reflectance FT infrared (IR) spectra were collected at room temperature on a Bruker IFS66 spectrometer equipped with a liquid nitrogen-cooled MCT detector at a spectral resolution of $4 \mathrm{~cm}^{-1}$ and accumulation of 1024 scans. An in situ cell (Harrick Praying Mantis ${ }^{\mathrm{TM}}$ diffuse reflectance attachment DRP-P72 in combination with a HVC-VUV reaction chamber) was used. $\mathrm{KBr}$ was used as reference material. The spectra were normalized using the silica band at $1865 \mathrm{~cm}^{-1}$.

Raman.

Confocal Raman spectra were collected at room temperature using a Horiba-Jobin Ybon LabRam instrument equipped with a red laser excitation $(633 \mathrm{~nm} / 1.96 \mathrm{eV}, 1.5 \mathrm{~mW}$ at the sample position). Spectral resolutions were better than $2 \mathrm{~cm}^{-1}$. An in situ cell (a home-made quartz cell) was used to measure the dehydrated state.

Prior to spectroscopic measurements, the samples were pretreated in dry oxygen ( $20 \mathrm{kPa}$, neat or diluted with a dry inert gas) at $823 \mathrm{~K}$ (heating rate $10 \mathrm{~K} \cdot \mathrm{min}^{-1}$ ) for $0.5 \mathrm{~h}$, then cooled to room temperatures in the presence of oxygen in order to achieve the fully oxidized and dehydrated state of the catalyst.

\section{Propene Metathesis and Post-reaction Active Site Counting}

\section{Propene metathesis}

The catalytic activity for the self metathesis of propene to ethene and 2-butenes was measured using a fixed-bed tube flow reactor at atmospheric pressure. All the gases were thoroughly dehydrated and deoxygenated (except oxygen) using trapping filters. The catalysts were pressed under $\sim 135 \mathrm{MPa}$, crushed and sieved to a particle size of $250-355 \mu \mathrm{m}$. Then, $100 \mathrm{mg}$ of the catalyst was loaded into a U-shaped quartz reactor with an inner diameter of $4 \mathrm{~mm}$. Guard beds consisting of silica gel (BET surface area $=428 \mathrm{~m}^{2} \mathrm{~g}^{-1}$ ) were placed both immediately above $(100 \mathrm{mg})$ and below $(50 \mathrm{mg})$ the catalyst bed in order to protect the catalyst bed from possible contamination by water. The use of the silica guard beds is essential to obtain a good catalytic performance. A blank test using bare SBA-15 with silica beds confirmed inertness of the apparatus and the guard beds. The catalyst was activated at $823 \mathrm{~K}$ (heating rate $10 \mathrm{~K} \cdot \mathrm{min}^{-1}$ ) for $0.5 \mathrm{~h}$, cooled to $323 \mathrm{~K}$ in a $20 \% \mathrm{O}_{2}$ in $\operatorname{Ar}\left(20 \mathrm{ml} \mathrm{min}^{-1}\right)$, and then flushed with a flow of $\operatorname{Ar}\left(20 \mathrm{ml} \mathrm{min}^{-}\right.$ ${ }^{1}$ ) before reaction. A neat propene flow of $8 \mathrm{ml} \mathrm{min}^{-1}$ was fed to start the reaction. Inlet and outlet gases were analyzed by on-line gas chromatography using an Agilent Technologies 6890A GC system equipped with a flame ionization detector. The conversion of propene was kept below $5 \%$ to stay in a differential regime. The selectivity to the metathesis products (ethane, cis- and trans-butene) was above $99.5 \%$, while trace amounts of 1-butene and higher hydrocarbons were detected. The activity is presented as formation rate of the metathesis products (i.e. sum of ethane, cis- and trans-butene) normalized by the BET surface area of the catalyst. The catalytic test was repeated after a regeneration procedure. The regeneration procedure is the same as the initial activation $\left(823 \mathrm{~K}\right.$ (heating rate $10 \mathrm{~K} \cdot \mathrm{min}^{-1}$ ) for $0.5 \mathrm{~h}$ and cooled to $323 \mathrm{~K}$ in a dehydrated $20 \% \mathrm{O}_{2}$ in $\mathrm{Ar}$, then flushed with $\mathrm{Ar}$ before starting the reaction). Error bars are estimated by two repeated measurements using fresh and regenerated catalysts.

\section{Active Site Counting by Post-reaction Ethene- $\boldsymbol{d}_{4}$ Metathesis}

After the metathesis reaction, the reactor was flushed with flowing $\operatorname{Ar}\left(20 \mathrm{ml} \mathrm{min}^{-1}\right.$ for $10 \mathrm{~min}$, then $5 \mathrm{ml} \mathrm{min}^{-1}$ for $\left.20 \mathrm{~min}\right)$, then the feed gas was switched to $5 \mathrm{ml} \mathrm{min}{ }^{-1}$ of $1 \% \mathrm{C}_{2} \mathrm{D}_{4}$ in Ar. The formation of propene$1,1-d_{2}$ was monitored and quantified with a quadrupole mass spectrometer (QMS200, Balzer) using the signal of $\mathrm{m} / \mathrm{z}=43$. The formation of propene-1,1- $d_{2}$ was also confirmed by the simultaneous detection of the molecular ion $(\mathrm{m} / \mathrm{z}=44)$. The two-fold amount of the liberated amount of propene-1,1- $d_{2}$ normalized by the BET surface are of the catalyst was assumed as the active site density.

\section{Post-reaction temperature programmed desorption}

After the active counting procedure, the reactor was flushed with flowing $\operatorname{Ar}(20 \mathrm{ml}$ $\mathrm{min}^{-1}$ for $30 \mathrm{~min}$ ) followed by a temperature ramp at rate of $10 \mathrm{~K} \mathrm{~min}^{-1}$ Evolved species are monitored by a mass spectrometer (QMS200, Balzer). Signal of $\operatorname{Ar}$ (m/e 40) was used as internal standard.

\section{Adsorption of Probe Molecules}

Prior to the adsorption, the samples were pretreated in dry oxygen (20 $\mathrm{kPa}$, neat or diluted with a dry inert gas) at $823 \mathrm{~K}$ (heating rate $10 \mathrm{~K} \cdot \mathrm{min}^{-}$ $\left.{ }^{1}\right)$ for $0.5 \mathrm{~h}$, then cooled to room temperatures in the presence of oxygen in order to achieve the fully oxidized and dehydrated state of the catalyst.

\section{Microcalorimetry of Propene Adsorption}

Differential heats of propene adsorption were determined at $323 \mathrm{~K}$ using a MS70 Calvet Calorimeter (SETRAM). The calorimeter was combined with a customdesigned high vacuum and gas dosing apparatus. Propene was stepwise introduced into the initially evacuated cell $\left(p<3 \cdot 10^{-6} \mathrm{~Pa}\right)$, and the pressure evolution and the heat signal were recorded for each dosing step. Though the propene was dosed at the reaction temperature for propene metathesis, possible thermal and volumetric contribution of the metathesis reaction can be neglected owing to the thermo- and stoichiometric-neutral nature of the reaction. ${ }^{[6 b]}$

\section{In situ IR for Adsorption of Propene and Ammonia}

Adsorption of propene and ammonia was studied by in situ FTIR spectroscopy. The IR experiments were carried out in transmission mode using a Perkin Elmer 100 FTIR spectrometer equipped with a DTGS detector at a spectral resolution of $4 \mathrm{~cm}^{-1}$ and accumulation of 64 scans The samples were pressed (125 MPa) into self-supporting wafers, which 
were placed in an in situ IR cell. The IR cell was directly connected to a vacuum system (residual pressure of $310^{-6} \mathrm{~Pa}$ ) equipped with a gas dosing line. Propene was dosed at $323 \mathrm{~K}$ at the pressure up to $3 \mathrm{hPa}$. Ammonia was dosed at $353 \mathrm{~K}$ at the pressure up to $7 \mathrm{hPa}$. In each experiment, the spectrum taken before probe dosing was used as background. Contribution of gas phase species was corrected by subtracting the spectrum without sample wafer. The spectra shown were normalized by the areal weight density of the wafer. The concentration of ammonia adsorption sites were estimated using the band at 1614 and $\sim 1430 \mathrm{~cm}^{-1}$ for Lewis acid sites and Brønsted acid sites, respectively.

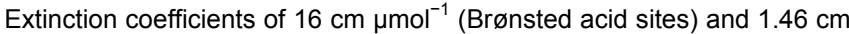
$\mathrm{mmol}^{-1}$ (Lewis acid sites) were used. ${ }^{[11]}$ Since the extinction coefficients have been taken from literature, the quantitative analysis of Lewis and Brønsted acid sites, respectively, represents a rough estimation.

\section{Temperature-Programmed Desorption of Ammonia ( $\mathrm{NH}_{3}-\mathrm{TPD}$ )}

Temperature-programmed desorption of ammonia ( $\mathrm{NH}_{3}$-TPD) was performed using a fixed bed reactor. About $30 \mathrm{mg}$ of catalyst was used. Adsorption of $\mathrm{NH}_{3}$ was done at $353 \mathrm{~K}$ by feeding $1 \% \mathrm{NH}_{3}$ in $\mathrm{Ar}(40$ $\mathrm{ml} / \mathrm{min}$ ) for $0.5 \mathrm{~h}$. After flushing the reactor with $\mathrm{He}$ at $353 \mathrm{~K}$ for $0.5 \mathrm{~h}$, the bed temperature was raised with a heating rate of $10 \mathrm{~K} / \mathrm{min}$ in $\mathrm{He}$ flow (40 ml/min). The desorption of $\mathrm{NH}_{3}$ was monitored by a quadrupole mass spectrometer (OmniStar GSD301, Pfeiffer) using the signal of $\mathrm{m} / \mathrm{e}=16$. The helium signal $(\mathrm{m} / \mathrm{e}=4)$ was used as internal standard.

\section{Acknowledgements}

We thank M. Hashagen, P. K. Nielsen, G. Lorenz and A. KleinHoffmann for their experimental assistance, and Prof. I. E. K. Wachs for fruitful discussion. K. Amakawa is grateful to Mitsubishi Gas Chemical Co. Inc. for a fellowship.

Keywords: heterogeneous catalysis - molybdenum - olefin metathesis $\cdot$ supported catalysts

[1] J. Ding, W. Hua, Chemical Engineering \& Technology 2013, 36, 83-90.

[2] J. C. Mol, Journal of Molecular Catalysis A: Chemical 2004, 213, 39-45.

[3] S. Lwin, I. E. Wachs, ACS Catalysis 2014, 4, 2505-2520.

[4] ${ }^{a}$ X. Zhu, X. Li, S. Xie, S. Liu, G. Xu, W. Xin, S. Huang, L. Xu, Catal Surv Asia 2009, 13, 1-8; ${ }^{b} D$. P. Debecker, M. Stoyanova, F. Colbeau-Justin,
U. Rodemerck, C. Boissière, E. M. Gaigneaux, C. Sanchez, Angewandte Chemie International Edition 2012, 51, 2129-2131.

[5] Y. Chauvin, Angewandte Chemie International Edition 2006, 45, 37403747.

[6] aJ. Handzlik, J. Ogonowski, Catalysis Letters 2003, 88, 119-122; ${ }^{b}$ K. Amakawa, S. Wrabetz, J. Kröhnert, G. Tzolova-Müller, R. Schlögl, A. Trunschke, Journal of the American Chemical Society 2012, 134, 11462-11473.

[7] D. P. Debecker, B. Schimmoeller, M. Stoyanova, C. Poleunis, P. Bertrand, U. Rodemerck, E. M. Gaigneaux, Journal of Catalysis 2011 277, 154-163.

[8] T. Hahn, U. Bentrup, M. Armbrüster, E. V. Kondratenko, D. Linke, ChemCatChem 2014, 6, 1664-1672.

[9] K. Amakawa, L. Sun, C. Guo, M. Hävecker, P. Kube, I. E. Wachs, S. Lwin, A. I. Frenkel, A. Patlolla, K. Hermann, R. Schlögl, A. Trunschke Angewandte Chemie International Edition 2013, 52, 13553-13557.

[10] J. Trébosc, J. W. Wiench, S. Huh, V. S. Y. Lin, M. Pruski, Journal of the American Chemical Society 2005, 127, 3057-3068.

[11] V. A. Matyshak, O. V. Krylov, Kinetics and Catalysis 2002, 43, 391-407.

[12] J. Herrera, J. Kwak, J. Hu, Y. Wang, C. Peden, Topics in Catalysis 2006, 39, 245-255

[13] F. Leydier, C. Chizallet, A. Chaumonnot, M. Digne, E. Soyer, A.-A. Quoineaud, D. Costa, P. Raybaud, Journal of Catalysis 2011, 284, 215229.

[14] M. Seman, J. N. Kondo, K. Domen, S. T. Oyama, Chemistry Letters 2002, 31, 1082-1083.

[15] F. Hemmann, I. Agirrezabal-Telleria, E. Kemnitz, C. Jäger, The Journal of Physical Chemistry C 2013, 117, 14710-14716.

[16] V. Crocellà, G. Cerrato, G. Magnacca, C. Morterra, The Journal of Physical Chemistry C 2009, 113, 16517-16529.

[17] X. Cao, R. Cheng, Z. Liu, L. Wang, Q. Dong, X. He, B. Liu, Journal of Molecular Catalysis A: Chemical 2010, 321, 50-60.

[18] aJ. Handzlik, The Journal of Physical Chemistry B 2005, 109, 2079420804; ' J. Handzlik, The Journal of Physical Chemistry C 2007, 111, 9337-9348.

[19] L. J. Gregoriades, J. Döbler, J. Sauer, The Journal of Physical Chemistry C 2010, 114, 2967-2979.

[20] K. A. Vikulov, B. N. Shelimov, V. B. Kazansky, J. C. Mol, Journal of Molecular Catalysis 1994, 90, 61-67.

[21] F. Blanc, N. Rendon, R. Berthoud, J.-M. Basset, C. Coperet, Z. J. Tonzetich, R. R. Schrock, Dalton Transactions 2008, 3156-3158.

[22] J. P. Thielemann, G. Weinberg, C. Hess, ChemCatChem 2011, 3, 1814-1821. 
Entry for the Table of Contents (Please choose one layout)

Layout 1:

\section{FULL PAPER}

Only ca. $1 \%$ of isolated distorted Mo di-oxo species that are in close vicinity to two silanol groups have been shown to be the precursor of the active carbene $(\mathrm{Mo}=\mathrm{CHR})$ sites on $\mathrm{MoO}_{\mathrm{x}} / \mathrm{SiO}_{2}$ catalysts for propene metathesis. Targeted active site creation resulted in an increase in initial catalytic activity by a factor of 800.

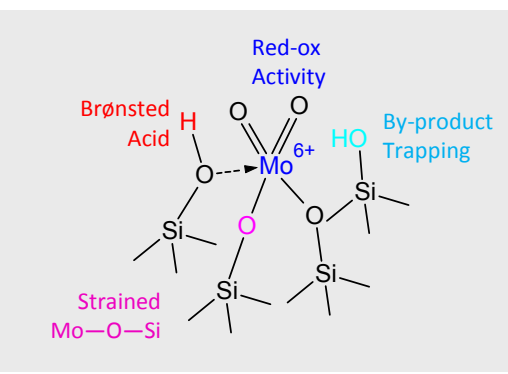

Dr. Kazuhiko Amakawa, Jutta Kröhnert, Dr. Sabine Wrabetz, Dr. Benjamin Frank Dr. Felix Hemmann,

Prof. Dr. Christian Jäger,

Prof. Dr. Robert Schlögl,

and Dr. Annette Trunschke*

Page No. - Page No.

Active Sites in Olefin Metathesis over Supported Molybdena Catalysts 